\title{
On Using Podcasting to Teach in Mobile Foreign Language Learning
}

\author{
Lu Sun ${ }^{1,} a^{*}$ \\ ${ }^{1}$ Harbin University of Commerce, Harbin, China, 150028 \\ aSUN_LU1980@163.com
}

Keywords: Podcasting; Internet; Mobile; Foreign language learning

\begin{abstract}
With the help of advanced Internet technologies, distance education and the use of new educational theory, podcasting, the new techniques have greatly enriched this area of foreign language teaching, expanded the foreign language mobile content and teaching methods. And it opens up a new idea on foreign language teaching reform. This article discusses the features of the podcasting, analyzes the instructional promotion effect through one representative case of educational podcasting of Apple Computer Inc., and proposes an implementation scheme and suggestions on it.
\end{abstract}

\section{Introduction}

Using the new educational theory, with the help of the advanced technology of the Internet, a variety of media to help foreign language teaching, reform teaching methods, improve the teaching effect, and always run through the development process of foreign language teaching. And this new technology in the near future, will greatly enrich the content and way of mobile foreign language teaching. Podcast is based on the development of the blog; some people call it the "voice of the blog", that the former is the evolution of the latter, from the category of Web2. 0. The two is the release of personal information through the Internet, and they need the help of a publisher, is usually provided by the third party information hosting service or to provide the corresponding service website for information dissemination and management. The foreign language teaching field and the traditional teaching facility have the very big limitation; only by the centralized classroom teaching already cannot completely satisfy the foreign language teaching the demand. And the podcast has opened a new line of thought for us.

\section{The Characteristics of the Podcast}

The production and use of the podcast is simple, technical requirements and economic costs are relatively low. Podcast creator collection of audio and video data, after editing program, upload to the network users; the corresponding podcasting software regularly check and update the content, downloaded to the local computer or portable music player, to watch and listen to, so that the formation of a podcast. The characteristics of the podcast are briefly summarized as:

Program production simple, economical and convenient. To produce a podcast, it needs a simple economy, including a multimedia computer, a microphone to collect audio (if necessary, a digital camera that can be equipped with a collection of videos) and a video production software. Where the production of software that can be downloaded on the Internet free version, but also a full range of powerful commercial version, can be selected according to the situation. With these you can easily make a video program, and then uploaded to provide the corresponding service network platform for their people to listen to, watch and download. Program production process is simple and easy to learn, easy for the public to master. A certain computer based people listening to watch podcast, if you are interested in this kind of radio, at any time can make their own podcast, become a member of the podcast.

To listen to the diversity and flexibility of the way to achieve the transmission of personal style. The nature of both the nature of the podcast and blog is attributed to the "root" of the people, that is, the way of personal communication. It makes it possible for the individual to spread to the public. 
In the information society, if the blog to subvert the passive acceptance of text mode, then the podcast has subverted the traditional passive tuning mode, realizes the information dissemination initiative: people can choose custom programs, and can give feedback on the program content, to express their views. On the one hand, users can use RSS to subscribe to their own interest in the podcast program, on the other hand, users can not only choose to listen, look at the content, you can also choose to listen to, watch the time and place. That is, you can listen to the computer before the watch; you can also download the program to the portable player, such as MP3, MP4 player, anytime, anywhere to listen to watch. This approach allows users to completely get rid of the fixed in front of the computer to listen to the stereotype of the watch, enhances the flexibility; and everyone can freely express their opinions and express themselves, can express their feelings by creating and uploading podcasts, timely feedback to the original author. It has changed the way of the past, one-way mass communication, the audience can take the initiative to choose the content and release information, the formation of the audience and the media between the equal two-way communication relationship.

\section{The Application of Teaching Examples of Podcast}

So far, the most far-reaching impact on the education of the podcast system is hosted by the famous Apple Computer Inc on the go Learning project. Apple Corp's educational podcast system not only provides portable MP3 and MP4 player terminal equipment and massive content resources, but also a set of mobile learning solutions based on constructivist learning theory as a support. It put his education plan for the podcast application terminal device to receive and process of learning management education in the virtual environment, simply summarized as: Podcasting=iPod+iTunes+iTunes $\mathrm{U}$, following which several links in education:

IPod player: terminal device for mobile learning, learners and teachers to use it in any teaching and learning takes place; the content of iTunes Education warehouse: iTunes is the integrated audio and video playback and resource management functions of the software, publishing and digital educational content can instantly download podcasts from the organization and content of teaching resources website the repository through its iTunes Store, in Mac or PC two platform to organize and play all content; iTunes $U$ click synchronous learning: can be understood as a virtual education environment and content distribution platform [1]. With it, the use of the content of education educational institutions to provide convenient ways for learners. By clicking on the relevant content, learners quickly get their own resources, to achieve the purpose of learning.

The "on iTunes U Stanford", which is built by the world famous University of higher learning, includes two sites: the Stanford campus internal site and the public site to the social public. Initially, Stanford in the range of campus construction and campus classroom district district two station. Classroom areas should be created by the University Teachers' requirements for private channels, in order to be registered in a specific class of users to use, curriculum administrators and instructors can upload and edit content, and students can only preview and download. Students can download the learning materials for several times: Lecture recording, music, interviews, video recording of a particular program, and other content that supports the teaching of the class. Students can download the contents of the teaching to the desktop computer, or download them to portable players and laptops for easy mobile learning. The campus area provides open space for the whole of Stanford, in order to share audio and video information. The school and the construction of the public site, using this system to publish course of lectures and campus events of the audio and video data to the alumni and the general public, the maintenance of the building, Stanford played a huge role in network community.

In the distance education experts published more "from distance learning to e-learning to mobile learning" in the text, the expression of mobile learning is a development trend in the future learning point of view, he believes that mobile learning is due to the increase of people geographical space mobility and flexible learning needs, the use of a mobile terminal equipment a new way of learning to learn [2]. Since then, mobile learning has been widely concerned as a new way of learning. The 
Apple Corp of the education podcasts its goal is "Learning on the go", this and our extensive discussion of "Mobile Learning" mean the same, can be interpreted as "mobile learning", it provides a solution for mobile learning, including hardware (personal computer terminal software (+iPod player) resource management software) and iTunes (iTunes Store), the content of resources and even provide a virtual education environment (iTunes $U$ ), formed a set of "Learning on the support system go".

\section{The Promotion of Foreign Language Teaching}

The podcasting and mobile learning devices currently in use, most can through wireless communication and Internet (via PDA or laptop), telecommunications network (through intelligent mobile phone) or TV broadcast network (via mobile Internet TV). Learners can access to the latest large number of foreign language learning resources in a variety of ways. Although some mobile learning devices (such as digital learning machine, MP3 /MP4 player) has no network connection function, but it has a lot of storage space and strong memory expansion ability, by downloading from the portal can also get enough multimedia foreign language learning resources.

The characteristics of the podcast are "portability" and "portability" ". The learners are no longer confined to the classroom, office or computer desk, at any time and any place on the move, as long as there is time to study, you can use a portable device with a flexible learning, so as to get rid of the limit of time and space constraints and the traditional teaching mode, fully embodies the advantages of mobile learning space.

Foreign language curriculum itself has a strong practical characteristics, to learn a foreign language can not be separated from a large number of language practice activities. For example, listening and speaking training is not only the language learning process, but also the process of skill training. It is not enough to rely on classroom learning for a large number of language practices, but also to have a lot of spare time to carry out. If the learner in a mobile environment, such as walking, queuing and waiting, waiting, travel and other non learning time, can use the hands of the podcast of foreign language learning, such as vocabulary, listening, listen and read, review, learning effect will be greatly improved, which is unmatched by the non language class of course. The practical activities of the foreign language curriculum can be carried out as long as the digital information such as voice, image and text can be carried out.

Learning a foreign language by using a podcast device, learners can have a great control over their autonomous learning. Whether it is learning content, learning progress or learning time, are fully in the hands of the learners. For example, the current penetration rate of high iPod, handheld computer can play audio and video, and has a A B repeat, fast forward, rewind, lyrics display and media selection function. Using these functions, learners can choose their own learning content according to their own actual situation, and fully reflect the advantages of learner centered learning.

With the construction and development of wireless mobile network, mobile communication tariffs continue to drop, the mobile terminal or mobile learning equipment price will be more expensive, each learner has a basic mobile learning device has one or several conditions are available, plus the foreign language study's practical advantages, learners only a few input can form a good language learning environment. Therefore, foreign language learning based on mobile information technology is easy to be popularized and popularized, especially in the use of spare time to study.

\section{The Use of English Language Teaching and Learning of the Recommendations of the Podcast}

The podcast has the conditions of application in foreign language teaching, and it has great potential to play a role in mobile learning, but its premise is to find a reasonable mode of application and teaching strategies. Only in combination with the characteristics of the podcast itself and the meaning of foreign language learning, the combination of the two, only to be able to truly Podcast. 


\section{Acknowledgements}

This paper is supported by Philosophy and Social Scientific Research Project Foundation of Heilongjiang Province (No.14C009).

\section{References}

[1] Avery.G. C, Leadership for Sustainable Futures Achieving Success in a Competitive World, first ed., Edward Elgar, 2010.

[2] Bacon.C. S, Enhancing Critical Thinking Skills through Conversation in the Classroom, J.Sci.Commun.11 (2011) 178-179.

[3] Cottrell. S, Critical Thinking Skills: Developing Effective Analysis and Argument, first ed., American Irwin, 2011.

[4] Cowen.T, Creative Destruction: How Globalization is changing the World's Cultures, first ed., Princeton University Press, 2012.

[5] Elsa Dent, The Leadership Pocketbook, first ed., Management Pocketbooks, 2003.

[6] Michalak.S. J, Liberal Education, J.Sci.Commun.156 (2011) 78.

[7] Quilliam. S, Positive Thinking, third ed., United States: DK Publishing, New York, 2008.

[8] Stamm. B. V, Managing, Innovation, Design, and Creativity, third ed., John Wiley \& Sons Ltd, Washington, 2003.

[9] Taylor. W. M, Informal Logic, J.Sci.Commun. 10 (2012) 19-22.

[10] Thompson. J. N, On Being a Successful Graduate Student, first ed., University of California, 2005. 